\title{
A COMMON FIXED POINT THEOREM FOR COMMUTING MAPPINGS
}

\begin{abstract}
SHIH-SEN CHANG
ABSTRACT. Results generalizing and unifying fixed point theorems of Jungck, Ciric, Das, Naik, Rhoades and Leader are established.
\end{abstract}

1. Introduction. Recently, some fixed point and common fixed point theorems for commuting mappings in complete metric spaces were proved by Jungck [1]-[3], Das, Naik [4], etc. The purpose of this paper is to generalize and unify some of these results.

2. Preliminaries. Throughout this paper let $(X, d)$ be a complete metric space, $f$ a self-mapping on $X$ such that for some positive integer $m f^{m}$ is continuous. Let $g_{i}$ : $f^{m-1}(X) \rightarrow X, i=1,2, \ldots$, be a sequence of mappings which commutes with $f$ and satisfies

$$
g_{i}\left(f^{m-1}(X)\right) \subset f^{m}(X), \quad i=1,2, \ldots .
$$

Further let there exist a sequence of positive integers $\left\{m_{i}\right\}_{i=1}^{\infty}$ such that for any positive integers $i, j$ and $x, y \in f^{m-1}(X)$ the following holds

$$
\begin{aligned}
& d\left(g_{i}^{m_{i}}(x), g_{j}^{m_{j}}(y)\right) \\
& \leqslant A\left(\operatorname { m a x } \left\{d(f(x), f(y)), d\left(f(x), g_{i}^{m_{1}}(x)\right), d\left(f(y), g_{j}^{m^{\prime}}(y)\right),\right.\right. \\
& \left.\left.\quad d\left(f(y), g_{i}^{m_{1}}(x)\right), d\left(f(x), g_{j}^{m^{\prime}}(y)\right)\right\}\right),
\end{aligned}
$$

where the function $A$ satisfies the following conditions (A1), (A2) or (A1), (A3):

(A1). $A:[0, \infty) \rightarrow[0, \infty)$ is nondecreasing and right continuous.

(A2). For any real number $q \in[0, \infty)$ there exists a suitable real number $t(q) \in[0, \infty)$ such that

(a) $t(q)$ is the upper bound of the set

$$
\{t \in[0, \infty): t \leqslant q+A(t)\},
$$

(b) $\lim _{n \rightarrow \infty} A^{n}(t(q))=0$.

(A3). For every $t>0, A(t)<t$ and

$$
\lim _{t \rightarrow \infty}(t-A(t))=\infty \text {. }
$$

It is easy to see that from (2.1) we have

$$
\begin{aligned}
g_{i}^{m_{i}} f^{m-1}(X) & =g_{i}^{m_{i}-1} g_{i} f^{m-1}(X) \subset g_{i}^{m_{i}-1}\left(f^{m}(X)\right) \\
& =g_{i}^{m_{i}-1} f^{m-1} f(X) \subset g_{i}^{m_{i}-1} f^{m-1}(X) \subset g_{i}^{m_{i}-2} f^{m}(X) .
\end{aligned}
$$

Received by the editors November 6, 1980 and, in revised form, February 25, 1981.

1980 Mathematics Subject Classification. Primary 54H25; Secondary 54A05. 
Repeating this procedure it follows that

$$
g_{i}^{m_{i}}\left(f^{m-1}(X)\right) \subset f^{m}(X), \quad i=1,2, \ldots
$$

Under the assumptions stated above, now we define a sequence of points $\left\{x_{n}\right\}$ as follows.

For any $x_{1} \in f^{m-1}(X)$ let $x_{2} \in f^{m-1}(X)$, guaranteed by (2.3), be such that $g_{1}^{m_{1}}\left(x_{1}\right)=f\left(x_{2}\right)$. Having defined $x_{n} \in f^{m-1}(X)$, let $x_{n+1} \in f^{m-1}(X)$ be such that

$$
g_{n}^{m_{n}}\left(x_{n}\right)=f\left(x_{n+1}\right), \quad n=1,2, \ldots
$$

Let

$$
y_{n}=g_{n}^{m_{n}}\left(x_{n}\right)=f\left(x_{n+1}\right), \quad n=1,2, \ldots
$$

Now we prove the following lemma.

LEMMA 1. Let $A$ satisfy conditions (A1) and (A2). Then the sequence $\left\{y_{n}\right\}_{n=1}^{\infty}$ defined by (2.4) is a Cauchy sequence in $X$.

Proof. Indeed, for any positive integers $i, j$ we have

$$
\begin{aligned}
d\left(y_{i}, y_{j}\right) & =d\left(g_{i}^{m_{i}}\left(x_{i}\right), g_{j}^{m_{3}}\left(x_{j}\right)\right) \\
& \leqslant A\left(\operatorname { m a x } \left\{d\left(f\left(x_{i}\right), f\left(x_{j}\right)\right), d\left(f\left(x_{i}\right), g_{i}^{m_{1}}\left(x_{i}\right)\right), d\left(f\left(x_{j}\right), g_{j}^{m}\left(x_{j}\right)\right),\right.\right. \\
& \left.\left.d\left(f\left(x_{j}\right), g_{i}^{m_{1}}\left(x_{i}\right)\right), d\left(f\left(x_{i}\right), g_{j}^{m_{3}}\left(x_{j}\right)\right)\right\}\right) \\
\leqslant A\left(\operatorname { m a x } \left\{d\left(y_{i-1}, y_{j-1}\right), d\left(y_{i-1}, y_{i}\right), d\left(y_{j-1}, y_{j}\right),\right.\right. & \left.\left.d\left(y_{j-1}, y_{i}\right), d\left(y_{i-1}, y_{j}\right)\right\}\right) .
\end{aligned}
$$

Thus by the assumption (A1), for any positive integers $m, n(m<n)$, we have

$$
\sup _{m<i, j<n} d\left(y_{i}, y_{j}\right) \leqslant A\left(\sup _{m-1<i, j<n} d\left(y_{i}, y_{j}\right)\right) \text {. }
$$

However

$$
\sup _{1<i, j<n} d\left(y_{i}, y_{j}\right) \leqslant d\left(y_{1}, y_{2}\right)+\sup _{2<i, j<n} d\left(y_{i}, y_{j}\right) \text {. }
$$

Taking $m=2$ in (2.5), it follows from (2.6) that

$$
\sup _{1<i, j<n} d\left(y_{i}, y_{j}\right) \leqslant d\left(y_{1}, y_{2}\right)+A\left(\sup _{1<i, j<n} d\left(y_{i}, y_{j}\right)\right) \text {. }
$$

Letting the real number $q=d\left(y_{1}, y_{2}\right)$ and using condition (A2) it follows from (2.7) that there exists a real number $t(q) \in[0, \infty)$ such that

$$
\sup _{1<i, j<n} d\left(y_{i}, y_{j}\right)<t(q) \text {. }
$$

Take $m=2$ in (2.5) again, and consider (2.8). Then we have

$$
\sup _{2<i, j<n} d\left(y_{i}, y_{j}\right) \leqslant A(t(q)) .
$$

Taking $m=3$ in (2.5) and using (2.9) it follows that

$$
\sup _{3<i, j<n} d\left(y_{i}, y_{j}\right)<A^{2}(t(q)) \text {. }
$$


Repeating this procedure, for any positive integers $m, n(m<n)$ we obtain

$$
\sup _{m<i, j<n} d\left(y_{i}, y_{j}\right) \leqslant A^{m-1}(t(q)) .
$$

Letting $m \rightarrow \infty$ (hence $n \rightarrow \infty$ ) in (2.11), from condition (A2) we obtain

$$
0 \leqslant \lim _{m \rightarrow \infty} \sup _{m<i, j<n} d\left(y_{i}, y_{j}\right) \leqslant \lim _{m \rightarrow \infty} A^{m-1}(t(q))=0 .
$$

This shows that $\left\{y_{i}\right\}$ is a Cauchy sequence in $X$.

LEMMA 2. Let $A$ satisfy the conditions (A1) and (A3). Then

(i) for every $t>0$ we have

$$
\lim _{n \rightarrow \infty} A^{n}(t)=0
$$

(ii) for any sequence $\left\{t_{n}\right\}$ of nonnegative real numbers satisfying the following condition

$$
t_{n+1} \leqslant A\left(t_{n}\right), \quad n=1,2, \ldots,
$$

we have $\lim _{n \rightarrow \infty} t_{n}=0$.

Remark 1. Lemma 2(i) was essentially obtained by Singh and Meade [5]. We include the proof for completeness.

Proof of Lemma 2. (i) For every $t>0$, (A3) yields $A(t)<t$. Repeating this procedure, we obtain

$$
A^{n}(t) \leqslant A^{n-1}(t)<\cdots<A(t)<t .
$$

By the right continuity of $A$ it follows that

$$
\lim _{n \rightarrow \infty} A^{n}(t)=\lim _{n \rightarrow \infty} A\left(A^{n-1}(t)\right)=A\left(\lim _{n \rightarrow \infty} A^{n-1}(t)\right) .
$$

Put $v=\lim _{n \rightarrow \infty} A^{n}(t)$. From the preceding relation we obtain $v=A(v)$. If $v \neq 0$, then it follows from (A3) that $v=A(v)<v$. This is a contradiction. Hence $v=0$, i.e. $\lim _{n \rightarrow \infty} A^{n}(t)=0$.

(ii) From the condition of Lemma 2, it is easy to see

$$
t_{n+1} \leqslant A\left(t_{n}\right) \leqslant A^{2}\left(t_{n-1}\right) \leqslant \cdots<A^{n}\left(t_{1}\right) .
$$

Letting $n \rightarrow \infty$ and using the conclusion (i) of Lemma 2, we obtain

$$
0 \leqslant \lim _{n \rightarrow \infty} t_{n+1} \leqslant \lim _{n \rightarrow \infty} A^{n}\left(t_{1}\right)=0 .
$$

This completes the proof of Lemma 2.

From Lemma 2 we can prove the following lemma.

Lemma 3. Let $A$ satisfy conditions (A1) and (A3). Then the sequence $\left\{y_{n}\right\}_{n=1}^{\infty}$ defined by (2.4) is also a Cauchy sequence in $X$.

Proof. By the preceding inequality (2.7) we can prove that

$$
\lim _{n \rightarrow \infty} \sup _{1<i, j<n} d\left(y_{i}, y_{j}\right)=\sup _{i, j>1} d\left(y_{i}, y_{j}\right)<\infty .
$$


Suppose this is not the case, therefore

$$
\lim _{n \rightarrow \infty} \sup _{1<i, j<n} d\left(y_{i}, y_{j}\right)=\infty .
$$

It follows from (A3) and (2.7) that

$$
\infty=\lim _{n \rightarrow \infty}\left(\sup _{1<i, j \leqslant n} d\left(y_{i}, y_{j}\right)-A\left(\sup _{1<i, j<n} d\left(y_{i}, y_{j}\right)\right)\right)<d\left(y_{1}, y_{2}\right) .
$$

This is a contradiction. This contradiction implies that

$$
\lim _{n \rightarrow \infty} \sup _{1<i, j<n} d\left(y_{i}, y_{j}\right)=\sup _{i, j>1} d\left(y_{i}, y_{j}\right)<\infty .
$$

Now we define a decreasing sequence of nonnegative real numbers

$$
t_{m}=\sup _{i, j>m} d\left(y_{i}, y_{j}\right), \quad m=1,2, \ldots
$$

From (2.5), we obtain

$$
t_{m} \leqslant A\left(t_{m-1}\right), \quad m=2,3, \ldots
$$

By Lemma 2(ii) this shows $t_{m} \rightarrow 0(m \rightarrow \infty)$, i.e.

$$
\lim _{m \rightarrow \infty} \sup _{i, j>m} d\left(y_{i}, y_{j}\right)=0 \text {. }
$$

Thus we have proved $\left\{y_{n}\right\}_{n=1}^{\infty}$ is a Cauchy sequence in $X$.

This completes the proof of Lemma 3.

3. Main results. We now formulate the main results of this paper as follows:

THEOREM 1. Let $(X, d)$ be a complete metric space, $f$ a self-mapping on $X$ such that for some positive integer $m f^{m}$ is continuous. Let $\left\{g_{i}\right\}_{i=1}^{\infty}: f^{m-1}(X) \rightarrow X$ be a sequence of mappings such that (2.1) is satisfied, and suppose $g_{i}$ commutes with $f$, $i=1,2, \ldots$ Further suppose there exists a sequence of positive integers $\left\{m_{i}\right\}_{i=1}^{\infty}$ such that for any positive integers $i, j$ and any $x, y \in f^{m-1}(X)(2.2)$ holds, where the function $A$ appearing in (2.2) satisfies the conditions (A1), (A2) or (A1), (A3). Then $f$ and $g_{i}, i=1,2, \ldots$, have a unique common fixed point $f\left(y_{*}\right)$, where $y_{*} \in X$ is the limit of the sequence $\left\{y_{n}\right\}_{n=1}^{\infty}$ defined by (2.4).

Proof. Since $A$ satisfies conditions (A1), (A2) (or (A1), (A3)), from Lemma 1 (or Lemma 3) the sequence $\left\{y_{n}\right\}_{i=1}^{\infty}$ defined by (2.4) is a Cauchy sequence in $X$. Suppose it converges to some point $y_{*}$ in $X$. By the continuity of $f^{m},\left\{f^{m}\left(y_{*}\right)\right\}$ converges to $f^{m}\left(y_{*}\right)$.

However by (2.4)

$$
g_{n}^{m_{n}}\left(f^{m-1}\left(y_{n-1}\right)\right)=g_{n}^{m_{n}}\left(f^{m}\left(x_{n}\right)\right)=f^{m}\left(g_{n}^{m_{n}}\left(x_{n}\right)\right)=f^{m}\left(y_{n}\right)
$$

and this implies

$$
\lim _{n \rightarrow \infty} g_{n}^{m_{n}}\left(f^{m-1}\left(y_{n-1}\right)\right)=\lim _{n \rightarrow \infty} f^{m}\left(y_{n}\right)=f^{m}\left(y_{*}\right) .
$$


COMMON FIXED POINT THEOREM FOR COMUTING MAPPINGS

649

Further, for any positive integer $i, i=1,2, \ldots$, we obtain from (3.1) that

$$
\begin{array}{r}
d\left(f^{m}\left(y_{n}\right), g_{i}^{m}\left(f^{m-1}\left(y_{*}\right)\right)\right)=d\left(g_{n}^{m_{n}}\left(f^{m-1}\left(y_{n-1}\right)\right), g_{i}^{m_{1}}\left(f^{m-1}\left(y_{*}\right)\right)\right) \\
\leqslant A\left(\operatorname { m a x } \left\{d\left(f^{m}\left(y_{n-1}\right), f^{m}\left(y_{*}\right)\right), d\left(f^{m}\left(y_{n-1}\right), g_{n}^{m_{*}}\left(f^{m-1}\left(y_{n-1}\right)\right)\right),\right.\right. \\
d\left(f^{m}\left(y_{*}\right), g_{i}^{m}\left(f^{m-1}\left(y_{*}\right)\right)\right), d\left(f^{m}\left(y_{*}\right), g_{n}^{m_{*}}\left(f^{m-1}\left(y_{n-1}\right)\right)\right), \\
\left.\left.d\left(f^{m}\left(y_{n-1}\right), g_{i}^{m_{1}}\left(f^{m-1}\left(y_{*}\right)\right)\right)\right\}\right) \\
\text { (3.3) } \quad \leqslant A\left(\operatorname { m a x } \left\{d\left(f^{m}\left(y_{n-1}\right), f^{m}\left(y_{*}\right)\right), d\left(f^{m}\left(y_{n-1}\right), f^{m}\left(y_{n}\right)\right),\right.\right. \\
d\left(f^{m}\left(y_{*}\right), g_{i}^{m}\left(f^{m-1}\left(y_{*}\right)\right)\right), d\left(f^{m}\left(y_{*}\right), f^{m}\left(y_{n}\right)\right), \\
\left.\left.d\left(f^{m}\left(y_{n-1}\right), g_{i}^{m_{1}}\left(f^{m-1}\left(y_{*}\right)\right)\right)\right\}\right) .
\end{array}
$$

Since

$$
\lim _{n \rightarrow \infty} f^{m}\left(y_{n}\right)=f^{m}\left(y_{*}\right)
$$

and

$$
\lim _{n \rightarrow \infty} g_{n}^{m_{n}}\left(f^{m-1}\left(y_{n-1}\right)\right)=f^{m}\left(y_{*}\right)
$$

then for any $\varepsilon>0$ there exists a positive integer $n_{0}$ such that for $n>n_{0}$ we have

$$
\begin{aligned}
d\left(f^{m}\left(y_{n-1}\right), f^{m}\left(y_{*}\right)\right) & <\frac{\varepsilon}{2}, \\
d\left(g_{n}^{m_{n}}\left(f^{m-1}\left(y_{n-1}\right)\right), f^{m}\left(y_{*}\right)\right) & <\frac{\varepsilon}{2} .
\end{aligned}
$$

Hence, for $n \geqslant n_{0}$, we have

$$
\begin{aligned}
d\left(f^{m}\left(y_{n}\right),\right. & \left.g_{i}^{m}\left(f^{m-1}\left(y_{*}\right)\right)\right) \\
& \leqslant A\left(\operatorname { m a x } \left\{\frac{\varepsilon}{2}, \varepsilon, d\left(f^{m}\left(y_{*}\right), g_{i}^{m}\left(f^{m-1}\left(y_{*}\right)\right)\right), \frac{\varepsilon}{2},\right.\right. \\
& \left.\left.\frac{\varepsilon}{2}+d\left(f^{m}\left(y_{*}\right), g_{i}^{m}\left(f^{m-1}\left(y_{*}\right)\right)\right)\right\}\right) \\
& \leqslant A\left(\varepsilon+d\left(f^{m}\left(y_{*}\right), g_{i}^{m}\left(f^{m-1}\left(y_{*}\right)\right)\right)\right) .
\end{aligned}
$$

First, letting $n \rightarrow \infty$ in the left side of (3.4) it follows that

$$
d\left(f^{m}\left(y_{*}\right), g_{i}^{m_{*}}\left(f^{m-1}\left(y_{*}\right)\right)\right) \leqslant A\left(\varepsilon+d\left(f^{m}\left(y_{*}\right), g_{i}^{m_{1}}\left(f^{m-1}\left(y_{*}\right)\right)\right)\right) \text {. }
$$

Next letting $\varepsilon \searrow 0$ in the right side of the preceding inequality and invoking the right continuity of $A$ we have

$$
d\left(f^{m}\left(y_{*}\right), g_{i}^{m_{3}}\left(f^{m-1}\left(y_{*}\right)\right)\right)<A\left(d\left(f^{m}\left(y_{*}\right), g_{i}^{m^{\prime}}\left(f^{m-1}\left(y_{*}\right)\right)\right)\right) .
$$

By (A3) this shows

$$
f^{m}\left(y_{*}\right)=g_{i}^{m_{*}}\left(f^{m-1}\left(y_{*}\right)\right), \quad i=1,2, \ldots
$$


Therefore from (3.5) we obtain

$$
\begin{gathered}
d\left(g_{i}^{m_{i}}\left(f^{m}\left(y_{*}\right)\right), f^{m}\left(y_{*}\right)\right)=d\left(g_{i}^{m_{1}}\left(f^{m}\left(y_{*}\right), g_{j}^{m}\left(f^{m-1}\left(y_{*}\right)\right)\right)\right. \\
<A\left(\operatorname { m a x } \left\{d\left(f^{m+1}\left(y_{*}\right), f^{m}\left(y_{*}\right)\right), d\left(f^{m+1}\left(y_{*}\right), f^{m+1}\left(y_{*}\right)\right),\right.\right. \\
d\left(f^{m}\left(y_{*}\right), f^{m}\left(y_{*}\right)\right), d\left(f^{m}\left(y_{*}\right), g_{i}^{m_{1} f^{m}}\left(y_{*}\right)\right), \\
\left.\left.\quad d\left(f^{m+1}\left(y_{*}\right), f^{m}\left(y_{*}\right)\right)\right\}\right) \\
=A\left(d\left(g_{i}^{m_{i}} f^{m}\left(y_{*}\right), f^{m}\left(y_{*}\right)\right)\right) .
\end{gathered}
$$

By (A3), this implies that

$$
g_{i}^{m_{1}}\left(f^{m}\left(y_{*}\right)\right)=f^{m}\left(y_{*}\right), \quad i=1,2, \ldots
$$

Now we prove $f^{m}\left(y_{*}\right)$ is the unique common fixed point of $f$ and $g_{i}, i=1,2, \ldots$ Indeed, in view of (3.5) and (3.6) we have

$$
f\left(f^{m}\left(y_{*}\right)\right)=f\left(g_{i}^{m^{\prime}}\left(f^{m-1}\left(y_{*}\right)\right)\right)=g_{i}^{m_{i}} f^{m}\left(y_{*}\right)=f^{m}\left(y_{*}\right) \text {. }
$$

On the other hand, for any $i, i=1,2, \ldots$, from (3.6) and (3.7) we have

$$
\begin{aligned}
& d\left(f^{m}\left(y_{*}\right), g_{i} f^{m}\left(y_{*}\right)\right)=d\left(g_{i}^{m_{i}} f^{m}\left(y_{*}\right), g_{i}^{m_{1}} g_{i}\left(f^{m}\left(y_{*}\right)\right)\right) \\
& \leqslant A\left(\operatorname { m a x } \left\{d \left(f^{m+1}\left(y_{*}\right), f\left(g_{i} f^{m}\left(y_{*}\right)\right), d\left(f^{m+1}\left(y_{*}\right), f^{m}\left(y_{*}\right)\right),\right.\right.\right. \\
& d\left(f g_{i} f^{m}\left(y_{*}\right), g_{i} f^{m}\left(y_{*}\right)\right), d\left(f g_{i} f^{m}\left(y_{*}\right), f^{m}\left(y_{*}\right)\right), \\
& \left.\left.d\left(f^{m+1}\left(y_{*}\right), g_{i} f^{m}\left(y_{*}\right)\right)\right\}\right) \\
& =A\left(\operatorname { m a x } \left\{d\left(f^{m}\left(y_{*}\right), g_{i} f^{m}\left(y_{*}\right)\right), 0,0\right.\right. \text {, } \\
& \left.\left.d\left(g_{i} f^{m}\left(y_{*}\right), f^{m}\left(y_{*}\right)\right), d\left(f^{m}\left(y_{*}\right), g_{i} f^{m}\left(y_{*}\right)\right)\right\}\right) \\
& =A\left(d\left(f^{m}\left(y_{*}\right), g_{i} f^{m}\left(y_{*}\right)\right)\right) \text {. }
\end{aligned}
$$

By (A3) from (3.8) we have

$$
f^{m}\left(y_{*}\right)=g_{i} f^{m}\left(y_{*}\right), \quad i=1,2, \ldots
$$

Combining (3.7) with (3.9), we obtain $f^{m}\left(y_{*}\right)$ is a common fixed point of $f$ and $g_{i}$, $i=1,2, \ldots$.

To prove $f^{m}\left(y_{*}\right)$ is the unique common fixed point of $f$ and $g_{i}$, we proceed as follows.

Suppose there exists another common fixed point $x_{*}$ of $f$ and $g_{i}, i=1,2, \ldots$, such that

$$
g_{i} x_{*}=x_{*}, \quad i=1,2, \ldots, \quad f x_{*}=x_{*}
$$


Consequently

$$
\begin{aligned}
d\left(x_{*}, f^{m}\left(y_{*}\right)\right)= & d\left(g_{i}^{m^{*}}\left(x_{*}\right), g_{j}^{m_{j} f^{m}}\left(y_{*}\right)\right) \\
\leqslant & A\left(\operatorname { m a x } \left\{d\left(f\left(x_{*}\right), f^{m+1}\left(y_{*}\right)\right), d\left(f\left(x_{*}\right), g_{i}^{m_{1}}\left(x_{*}\right)\right),\right.\right. \\
& d\left(f^{m+1}\left(y_{*}\right), g_{j}^{m_{j} f^{m}}\left(y_{*}\right)\right), \\
& \left.\left.\quad d\left(f^{m+1}\left(y_{*}\right), g_{i}^{m_{*}}\left(x_{*}\right)\right), d\left(f\left(x_{*}\right), g_{j}^{m_{3}}\left(f^{m}\left(y_{*}\right)\right)\right)\right\}\right) \\
= & A\left(\max \left\{d\left(x_{*}, f^{m}\left(y_{*}\right)\right), 0,0, d\left(f^{m}\left(y_{*}\right), x_{*}\right), d\left(x_{*}, f^{m}\left(y_{*}\right)\right)\right\}\right) \\
= & A\left(d\left(x_{*}, f^{m}\left(x_{*}\right)\right)\right) .
\end{aligned}
$$

It implies $x_{*}=f^{m}\left(y_{*}\right)$.

This completes the proof of Theorem 1 .

From Theorem 1 we can easily deduce the following corollary.

Corollary. Let $(X, d)$ be a complete metric space, $f$ a self-mapping on $X$ such that for some positive integer $m, f^{m}$ is continuous. Let $\left\{g_{i}\right\}_{i=1}^{\infty}: f^{m-1}(X) \rightarrow X$ be a sequence of mappings such that (2.1) is satisfied, and suppose $g_{i}$ commutes with $f$, $i=1,2, \ldots$ Further suppose there exists a sequence of positive integers $\left\{m_{i}\right\}_{i=1}^{\infty}$ such that for any positive integer $i, j$ and any $x, y \in f^{m-1}(X)$ the following holds:

$$
\begin{array}{r}
d\left(g_{i}^{m_{i}}(x), g_{j}^{m^{\prime}}(y)\right) \leqslant k \max \left\{d(f(x), f(y)), d\left(f(x), g_{i}^{m_{i}}(x)\right), d\left(f(y), g_{j}^{m^{3}}(y)\right),\right. \\
\left.d\left(f(y), g_{i}^{m_{i}}(x)\right), d\left(f(x), g_{j}^{m_{3}}(y)\right)\right\},
\end{array}
$$

where $k$ is a constant: $0<k<1$.

Then the conclusion of Theorem 1 still holds.

Proof. Taking $A(t)=k t, t \geqslant 0$, it is easy to see that $A(t)$ satisfies the assumptions (A1), (A2), (A3). Therefore the conclusion of the Corollary follows from the theorem.

Remark 2. The results of Das and Naik [4, Theorem 2.1, Theorem 3.1, Theorem 3.2 and Theorem 4.1], Ciric [6, Theorem 1 and Theorem 2], Jungck [3], Rhoades [7, Theorem 23] are all special cases of our Corollary.

In a sense, the theorem in this paper is also a generalization and improvement of Cheh-chih Yen [8], Murakami and Cheh-chih Yen [9] and Leader [10].

\section{REFERENCES}

1. G. Jungck, A common fixed point theorem for commutting maps on L-spaces, Math. Japon. 25 (1980), 81-85.

2. Periodic and fixed points, and commuting mappings, Proc. Amer. Math. Soc. 76 (1979), $333-338$.

3. Commuting mappings and fixed points, Amer. Math. Monthly 83 (1976), 261-263.

4. K. M. Das and K. Viswanatha Naik, Common fixed point theorems for commuting maps on a metric space, Proc. Amer. Math. Soc. 77 (1979), 369-374.

5. S. P. Singh and B. A. Meade, On common fixed point theorems, Bull. Austral. Math. Soc. 16 (1977), 49-53. 
6. B. Ciric, A generalization of Banach's contraction principle, Proc. Amer. Math. Soc. 45 (1974), 267-273.

7. B. E. Rhoades, Comparison of various definitions of contractive mappings, Trans. Amer. Math. Soc. 226 (1977), 256-290.

8. Cheh-chih Yen, Some fixed point theorem in complete metric spaces, Math. Japon. 23 (1978), $27-31$.

9. H. Murakami and Cheh-chih Yen, Fixed point theorems in complete metric spaces, Math. Japon. 23 (1978), 77-83.

10. S. Leader, Fixed points for general contractions in metric spaces, Math. Japon. 24 (1979), 17-24.

Department of Mathematics, Sichuan University, Chengdu, Sichuan, 610064, People's RepubLIC OF CHINA 